\title{
Testing animal-assisted cleaning prior to transplantation in coral reef restoration
}

Sarah Frias-Torres, Casper van de Geer

Rearing coral fragments in nurseries and subsequent transplantation onto a degraded reef is a common approach for coral reef restoration. However, if barnacles and other biofouling organisms are not removed prior to transplantation, fish will dislodge newly cemented corals when feeding on biofouling organisms. This behavior can lead to an increase in diver time due to the need to reattach the corals. Thus, cleaning nurseries to remove biofouling organisms such as algae and invertebrates is necessary prior to transplantation, and this cleaning constitutes a significant time investment in a restoration project. We tested a novel biomimicry technique of animal-assisted cleaning on nursery corals prior to transplantation at a coral reef restoration site in Seychelles, Indian Ocean. To determine whether animal-assisted cleaning was possible, preliminary visual underwater surveys were performed to quantify the fish community at the study site. Then, cleaning stations consisting of nursery ropes carrying corals and biofouling organisms, set at $0.3 \mathrm{~m}, 2 \mathrm{~m}, 4 \mathrm{~m}, 6 \mathrm{~m}$ and $8 \mathrm{~m}$ from the seabed, were placed at both the transplantation (treatment) site and the nursery (control) site. Remote GoPro video cameras recorded fish feeding at the nursery ropes without human disturbance. A reef fish assemblage of 32 species from 4 trophic levels (18.8\% herbivores, $18.8 \%$ omnivores, $59.3 \%$ secondary consumers and $3.1 \%$ carnivores) consumed $95 \%$ of the barnacles on the coral nursery ropes placed $0.3 \mathrm{~m}$ above the seabed. Using this cleaning station, we reduced coral dislodgement from $16 \%$ to zero. This cleaning station technique could be included as a step prior to coral transplantation worldwide on the basis of location-specific fish assemblages and during the early nursery phase of sexually produced juvenile corals. 


\section{Testing animal-assisted cleaning prior to transplantation in coral}

\section{2 reef restoration}

3

4 Sarah Frias-Torres ${ }^{a, b, ~ *}$, Casper van de Geer ${ }^{a, c}$

5 a Nature Seychelles, Island Conservation Centre, Amitie, Praslin, Republic of Seychelles

6 b Smithsonian Marine Station, 701 Seaway Drive, Fort Pierce, Florida 34949, USA

$7 \quad$ c Local Ocean Trust, Plot 203, Watamu, Kenya

8

9 *Corresponding author:

10 Tel: Seychelles (+248) 278-08-11; USA (+1) 772-462-6220

11 E-mail address: sfriastorres@gmail.com

12

13 Keywords:

14 Barnacle

15 Biofouling

16 Biomimicry

17 Cleaning station

18 Coral gardening

19 Indian Ocean

20 Nursery

21 Seychelles

22 Transplantation 


\section{ABSTRACT}

Rearing coral fragments in nurseries and subsequent transplantation onto a degraded reef is a common approach for coral reef restoration. However, if barnacles and other biofouling organisms are not removed prior to transplantation, fish will dislodge newly cemented corals when feeding on biofouling organisms. This behavior can lead to an increase in diver time due to the need to reattach the corals. Thus, cleaning nurseries to remove biofouling organisms such as algae and invertebrates is necessary prior to transplantation, and this cleaning constitutes a significant time investment in a restoration project. We tested a novel biomimicry technique of animal-assisted cleaning on nursery corals prior to transplantation at a coral reef restoration site in Seychelles, Indian Ocean. To determine whether animal-assisted cleaning was possible, preliminary visual underwater surveys were performed to quantify the fish community at the study site. Then, cleaning stations consisting of nursery ropes carrying corals and biofouling organisms, set at $0.3 \mathrm{~m}, 2 \mathrm{~m}, 4 \mathrm{~m}, 6 \mathrm{~m}$ and $8 \mathrm{~m}$ from the seabed, were placed at both the transplantation (treatment) site and the nursery (control) site. Remote GoPro video cameras recorded fish feeding at the nursery ropes without human disturbance. A reef fish assemblage of 32 species from 4 trophic levels $(18.8 \%$ herbivores, $18.8 \%$ omnivores, $59.3 \%$ secondary consumers and $3.1 \%$ carnivores) consumed $95 \%$ of the barnacles on the coral nursery ropes placed $0.3 \mathrm{~m}$ above the seabed. Using this cleaning station, we reduced coral dislodgement from $16 \%$ to zero. This cleaning station technique could be included as a step prior to coral transplantation worldwide on the basis of location-specific fish assemblages and during the early nursery phase of sexually produced juvenile corals.

\section{Introduction}


47 Active coral reef restoration is increasingly being seen as a new tool for conservation biology

48 (Precht 2006) as coral reefs continue to decline worldwide (Hoegh-Guldberg 2004). One of the

49 several available coral reef restoration methods involves "coral gardening" in a two-step process. First, coral fragments are raised in underwater nurseries. Second, after reaching a target size, the nursery corals are harvested and transplanted onto degraded reef areas (Rinkevich 2006).

The cleaning of algae and sessile invertebrates (sponges, hydroids, barnacles, mollusks, and tunicates) in nurseries is essential to avoid the space competition with corals, which leads to shading and coral death. Nursery cleaning consumes a significant portion of the time invested in restoration projects (Precht 2006). Prior to transplantation onto reefs, the nursery corals require additional cleaning. Grazers and invertivores at the nursery site and adjacent natural reefs can potentially consume biofouling organisms, which reduces the need for human maintenance of the nurseries and cleaning prior to transplantation (Shafir et al. 2010).

Animal-assisted cleaning to control fouling organisms in coral culture has been performed while rearing coral juveniles settled from sexual reproduction. In ocean (in situ) nurseries, polyps of Acropora tenuis have been co-cultured with hatchery-supplied juveniles of the top shell Trochus niloticus (Omori 2005, Omori et al. 2007). In laboratory (ex situ) nurseries, polyps of Pocillopora damicornis have been co-cultured with juveniles of the sea urchin Salmacis spaheroides and the gastropod Trochus maculatus collected from the wild (Toh et al. 2013).

Both experiments have shown that the introduction of grazers under co-culture conditions controls algal proliferation, effectively increasing the survival of coral juveniles during their first 4 months of life. This period is critical in coral culture due to the vulnerability of juvenile corals, 
which may die due to smothering by filamentous algae. However, quantification of animalassisted cleaning by coral reef fishes in the wild has not been tested until now.

In a large-scale coral reef restoration project in Seychelles (Indian Ocean), we deployed 9 midwater rope nurseries, following methodology modified from Levy et al. (2010). Ropes loaded with farmed corals obtained through asexual propagation (fragments from donor colonies and rescued corals dislodged by storms or human activity) were floated $8 \mathrm{~m}$ below the sea surface to form a rope nursery. The entire structure was moored to angle bars hammered into the $17 \mathrm{~m}$-deep sandy seabed. Each rope nursery held approximately 5,000 corals. The cleaning of biofouling organisms at each midwater rope nursery required $22.7 \pm 9.78($ mean $\pm \mathrm{SD}, \mathrm{n}=9)$ diver hours (range 12-36 diver hours) per month. Biofouling cleaning was repeated every 2-4 months. When we used a different type of midwater coral nursery (6x6 m PVC pipe frames layered with $5.5 \mathrm{~cm}-$ mesh tuna nets), reef fishes recruited at the nurseries consumed the biofouling organisms and reduced the required cleaning time (Frias-Torres et al. 2015). Net nurseries filled with corals provided a three-dimensional patch of habitat that facilitated the recruitment of resident fish. The lack of the three-dimensional habitat patch in the rope nurseries might explain why no resident fish community was recruited there, which made the periodic removal of biofouling organisms a necessity.

While cleaning the biofouling organisms at the midwater rope nurseries, we found that barnacles attached to the nursery ropes and to the coral/rope boundary were difficult to remove. After cementing nursery-raised corals to the reef restoration site, a mob of fish rammed the newly cemented corals to feed on mobile invertebrates that were recruited during the nursery phase or 
93

94

95

96

97

98

99

100

101

102

103

104

105

106

107

108

109

110

111

112

113

114

115

any leftover barnacles. The ramming fish species included the Sky Emperor (Lethrinus

mahsena), Tripletail Wrasse (Cheilinus trilobatus), Titan Triggerfish (Balistoides viridescens)

and flagtail triggerfish (Sufflamen chrysopterum; Table 1). Based on our dive logs, where we

recorded the number of corals that were cemented and dislodged after each dive, coral

dislodgement due to such fish attacks began when 13,140 corals were transplanted and increased

to $16 \%$ of newly cemented corals when we reached 19,745 transplanted corals. This increase in

coral dislodgement required repeating the cementing process towards the end of each dive, and

hence, the total dive time required to complete our transplantation schedule increased (Fig. 1).

Based on these field observations (the time invested in cleaning nurseries and coral dislodgement by fish), we searched for a biomimicry solution, i.e., a solution inspired by nature, to develop an innovative and sustainable technique (Benyus 2002). Our inspiration was the cleaning stations at coral reefs where fish, sea turtles, sharks and rays congregate to be cleaned of parasites by cleaner fish and shrimps (Gorlick et al. 1987, Losey et al. 1994, O’Shea et al. 2010). Therefore, we systematically investigated the ability of coral reef fish to provide animal-assisted cleaning at coral nursery ropes prior to transplantation. Specifically, we hypothesized that 1) animal-assisted cleaning would occur closer to the bottom rather than higher in the water column, and 2) more animal-assisted cleaning would occur at the coral restoration site than at the nursery site because the periodic need to clean biofouling organisms at nurseries might result in a lack of an adequate biofouling-cleaning community at the nursery site. Here, we describe a novel technique for animal-assisted cleaning of nursery corals using a cleaning station. This new technique could be applied in coral reef restoration projects, particularly prior to the transplantation of corals on the reef and in the early nursery phase of sexually produced juvenile corals. 
117 Materials and methods

118

119 Field settings

120

121 This animal-assisted cleaning technique was developed as a result of two experiments conducted

122 between 3-18 December 2013 at a coral reef restoration project within the marine protected area

123 of Cousin Island Special Reserve, Seychelles, Indian Ocean (04 $19^{\prime} 35^{\prime \prime} \mathrm{S}$; $055^{\circ} 39^{\prime} 24^{\prime \prime}$ E;

124 Fig. 2).

125

126 The restoration project included a nursery site and a reef transplantation site. The nursery site,

127 located on the north-west side of the island at approximately $1 \mathrm{~km}$ from the nearest coral reef,

128 included 9 mid-water rope nurseries. Each mid-water rope nursery consisted of 5 high-pressure

129 PVC pipes (HP PVC), $600 \times 64 \mathrm{~mm}$ in size, placed approximately $4 \mathrm{~m}$ apart, to which $20 \mathrm{~m}-1$ long

130 ropes were perpendicularly attached. Each rope held 80-150 corals, totaling approximately 5,000

131 corals in each rope nursery. The nurseries were attached to the $17 \mathrm{~m}$-deep sandy seabed by

132 anchor lines and maintained at a depth of $8 \mathrm{~m}$ below the sea surface by using recycled plastic

133 jerrycans as buoys. The reef transplantation site, located on the south-west side of the island,

134 consisted of a degraded coral reef affected by the mass coral bleaching event of the 1998, due to

135 the coupling of the El Niño and the Indian Ocean Dipole (Spencer et al. 2000; Spalding \& Jarvis

136 2002) as well as the 2004 Indian Ocean Tsunami (Jackson et al. 2005). At this site, a gentle slope

137 (roughly $25^{\circ}$ ) extends to a depth of $13 \mathrm{~m}$. The seabed then flattens out and consists of a mixture

138 of sand and coral rubble interspersed with granite outcroppings. The coral colonies grown in the 
139 midwater rope nurseries were transplanted to this degraded reef. At the time of the experiment,

140 the transplantation site had been changed from a flattened-out degraded state to include 19,745

141 transplanted coral colonies of the following species: Acropora cytherea, A. damicornis, A.

142 formosa, A. hyacinthus, A. abrotanoides, A. lamarki, A. vermiculata, Pocillopora damicornis, $P$.

143 indiania and $P$. grandis.

145 Methods

147 A field permit was not required to conduct the experiments described herein at the marine reserve within the Cousin Island Special Reserve. The Special Reserve is managed by Nature

Seychelles. As Nature Seychelles employees, we were able to perform underwater observations without the issuing of a specific permit at the no-take marine reserve, as long as we complied with the demands for no damage, harassment or taking of fish.

152

153 To test the animal-assisted cleaning of the nursery corals, we first assessed fish diversity at the 154 transplantation site to determine whether the fish community could provide animal-assisted cleaning; then, we performed field experiments to quantify animal-assisted cleaning. To assess fish diversity at the transplantation site, we conducted visual underwater surveys via the standard

157 point count method (Jennings et al. 1996, Hill and Wilkinson 2004, Ledlie et al. 2007). Briefly, 158 divers were located at random points within the area, where they laid out a $7.5 \mathrm{~m}$ tape to form the 159 radius of an imaginary cylinder and remained neutrally buoyant approximately $2 \mathrm{~m}$ off the 160 seabed. All of the fish entering the $7.5 \mathrm{~m}$ cylinder radius were counted for 6 minutes and 161 identified to the species level. During the seventh minute, each diver recorded cryptic fish 
162 species (hiding in the substrate) while swimming in a spiral from the center of the cylinder

163 outwards. These point method counts were replicated six times.

164

165 To investigate animal-assisted cleaning, we developed an experimental unit resembling a ladder

166 (Fig. 3, video in Supporting Information). Angle bars were driven into the seabed $1.8 \mathrm{~m}$ apart,

167 and mooring lines with buoys (recycled jerrycans filled with air and capped) were vertically

168 attached to each angle bar. Ropes with nursery corals and biofouling organisms were then

169 horizontally tied between the mooring lines like rungs on a ladder, at $0.3 \mathrm{~m}, 2 \mathrm{~m}, 4 \mathrm{~m}, 6 \mathrm{~m}$ and 8

$170 \mathrm{~m}$ from the seabed. The experimental units were deployed at the nursery site (control) and the

171 transplantation site (treatment) with 3 replicates per site. To avoid pseudo-replication, each

172 experimental unit was placed at a different location within each site, and each replicate was

173 arranged with a new set of coral nursery ropes. At the transplantation site, the experimental units

174 were deployed on 9 December (2 locations) and 11 December 2013 (1 location). At the nursery

175 site, the experimental units were deployed on 16 December (2 locations) and 18 December 2013

176 (1 location). The experimental rungs were cut from $20 \mathrm{~m}$-long coral ropes from a midwater

177 nursery filled with corals of opportunity (i.e., corals rescued from the seabed after breakage due

178 to storms or anchor damage). The coral species included Acropora bruegemanni, A. formosa, A.

179 abrotanoides, A. nobilis and A. robusta. The corals grew at the nursery for 17 months, and their

180 size was $15.6 \pm 4.51 \mathrm{~cm}($ mean $\pm \mathrm{SD})$ at their maximum dimension (range, $11.5-21 \mathrm{~cm})$.

181 Therefore, the experimental units allowed the concept of a cleaning station to be tested by depth 182 and site. 
184 Small underwater cameras (GoPro) were placed next to the experimental units to remotely

185 document the fish interacting with the nursery ropes without human disturbance. To analyze the

186 fish assemblages at the transplantation site using underwater visual surveys and video recordings

187 performed at the experimental units (both the transplantation and nursery sites), we generated an

188 inventory of fish species and compared the video-recorded feeding behavior of each species to

189 known trophic levels and food items reported in FishBase (http://www.fishbase.org) and

190 Encyclopedia of Life (http://www.eol.org). In FishBase, the mean trophic position is calculated

191 based on all the food items consumed by a species, weighted by their relative abundance. The

192 trophic level is obtained by adding 1 to the mean trophic position (Froese \& Pauly 2014). The

193 range of trophic levels is as follows: 1 for primary producers, 2-2.19 for primary consumers

194 (herbivores consuming mainly plants or detritus), 2.2-2.79 for omnivores (consuming plants or

195 detritus and animals), 2.8-4 for secondary consumers and higher than 4 for tertiary consumers

196 (carnivores).

197

198 To quantify animal-assisted cleaning, we counted the number of corals and barnacles on each of

199 the nursery ropes prior to their placement at both sites (nursery and transplantation). The

200 experimental units were then left in situ for $48 \mathrm{~h}$, after which the number of barnacles was

201 counted again, and the coral colonies were closely examined for signs of damage or predation.

202 Barnacles were considered "eaten" when their calcareous exoskeletons were crushed and no

203 barnacle soft tissue was present. Photographs of selected barnacle clumps and coral colonies

204 were also taken before and after deployment for visual comparison.

205 
206

207

208

209

210

211

212

213

214

215

216

217

218

219

220

221

222

223

224

225

226

227 The field experiments revealed that the thornback boxfish (Lactoria fornasini, Ostraciidae) was 228 the only species that was video recorded interacting with the experimental setup at the nursery

Due to the variable number of barnacles per rope, the count data were converted into the percentage of barnacles eaten per rope. To meet the assumptions of parametric statistical analysis, the percentages were ArcSin transformed (Sokal \& Rohlf 1995). We tested the null hypothesis of no differences in the mean percentage of barnacles eaten per site and by depth using the transformed data in a two-way analysis of variance (ANOVA) model I (fixed factors). Post hoc comparisons were performed with Tukey’s Honestly Significant Difference (HSD) Test.

\section{Results}

The fish community at the transplantation site was diverse (51 species) and was dominated by wrasses (Labridae, 12 species; Fig. 4a). Other families present included surgeonfishes (Acanthuridae, 5 species), groupers (Serranidae, 4 species), damselfishes (Pomacentridae, 4 species), butterflyfishes (Chaetodonthidae, 4 species), triggerfishes (Balistidae, 3 species), goatfishes (Mullidae, 2 species), angelfishes (Pomacanthidae, 2 species) and dartfishes (Microdesmidae, 2 species). A total of 13 families were represented by only 1 species each. The species classified by trophic level included $11.8 \%$ herbivores, $15.7 \%$ omnivores, $50.9 \%$ secondary consumers and $21.6 \%$ carnivores. Based on these results, we determined that the transplantation site harbored a fish community capable of feeding on the biofouling organisms accumulated on the coral nursery ropes. Hence, we proceeded with the quantification of the animal-assisted biofouling cleaning using the experimental setup. 
229 site. This species feeds on benthic invertebrates and has a trophic level of $3.0 \pm 0.0$ (Froese \&

230 Pauly 2010; FishBase data http://www.fishbase.org). Four additional species were video

231 recorded at the nursery site but did not interact with the experimental setup: emperors (Lethrinus

232 sp., Lethrinidae), goatfishes (Parupeneus sp., Mullidae), razorfishes (Xyrichtys $s p$. Labridae) and

233 porcupinefishes (Diodon sp., Diodontidae). However, at the transplantation site, 32 fish species

234 were observed feeding at the experimental setup (Fig. 4b, Fig. 5, and Table 1). Here, the video-

235 recorded fish community (Fig. 5, video) was a subset of the species recorded during the visual

236 underwater surveys and was also dominated by wrasses (Labridae, 7 species). Other families

237 included surgeonfishes (Acanthuridae, 4 species), triggerfishes (Balistidae, 3 species),

238 angelfishes (Pomacanthiade, 2 species), butterflyfishes (Chaetodontidae, 2 species), rabbitfishes

239 (Siganidae, 2 species), pufferfishes (Tetraodontidae, 2 species), and porcupinefishes

240 (Diodontidae, 2 species). A total of 8 families were represented only by 1 species each. The

241 species classified by trophic level included $18.8 \%$ herbivores, $18.8 \%$ omnivores, $59.3 \%$

242 secondary consumers and $3.1 \%$ carnivores.

243

244 The only species that was observed breaking and feeding on the barnacles attached to the ropes

245 was the Titan Triggerfish (Balistoides viridescens; Fig. 5). Other biofouling predators were

246 observed feeding on barnacle remains after the calcareous exoskeleton was broken by $B$.

247 viridescens but otherwise fed on algae and sessile and mobile invertebrates attached to the ropes.

248 No other animals were observed to interact with the experimental unit, although octopuses and

249 sea turtles were recorded in the vicinity. The Humphead Parrotfish (Bolbometopon muricatum), a

250 coral predator, was not video-recorded at the nursery or transplantation sites; however, it was a

251 regular visitor feeding on biofouling fragments falling to the seabed when divers cleaned the 
252 nurseries. After the 48 hour-long experiment, predation of corals (indicated by scarring or bite

253 marks) was absent at both the transplantation and nursery sites.

254

255 Each 1.8 m-long rung in the experimental units harbored a similar number of corals: $13.4 \pm 1.68$

256 (mean $\pm \mathrm{SD}$ ) corals per rung at the transplantation site (range 10-16 corals) and 13.5 \pm 1.84

257 corals per rung at the nursery site (range 10-17 corals). Despite these similar numbers of corals

258 per rung, the average number of live and dead corals per rung varied. For instance, there were

$2597.9 \pm 3.93($ mean \pm SD) live corals per rung (range 2-14 corals) and $5.4 \pm 4.22$ dead corals per

260 rung (range 1-14 corals) at the transplantation site, whereas there were $7.2 \pm 3.43$ live corals per

261 rung (range 1-13 corals) and 6.2 \pm 4.16 dead corals per rung (range 1-15 corals) at the nursery

262 site. However, the differences were not significant (two-way ANOVA model I) between the

263 transplantation and nursery sites $\left(\mathrm{F}_{1,56}=2.88 ; \mathrm{p}=0.09\right)$ and between the number of dead and live

264 corals per rung $\left(\mathrm{F}_{1,56}=0.004 ; \mathrm{p}=0.94\right)$. Therefore, each independent replicate provided the same

265 feeding substrate under the experimental field conditions.

266

267 Barnacle predation at the transplantation (treatment) site was 3.25 times higher overall than at 268 the nursery (control) site $\left(38.8 \% \pm 0.21 \mathrm{SE}\right.$ and $12.2 \% \pm 0.03 \mathrm{SE}$, respectively; $\mathrm{F}_{1,20}=15.33$, $269 \mathrm{p}=0.0008)$. The depth of placement was critical. The highest barnacle predation was observed at

270 the transplantation site on the $0.3 \mathrm{~m}$ ropes $(94.8 \% \pm 2.7$ S.E) and the $2 \mathrm{~m}$ ropes $(83.3 \% \pm 9.3$

271 S.E.; $F_{4,20}=6.54, p=0.002$; Fig. 3). The site $x$ depth interaction was significant $\left(\mathrm{F}_{4,20}=10.16\right.$,

$272 \mathrm{p}=0.0001)$. Post hoc comparisons of the interaction term using Tukey's HSD test revealed that

273 barnacle predation at the transplantation site was similar on the 0.3 and $2 \mathrm{~m}$ ropes $(\mathrm{p}=0.99)$, but 
274 it was 5 to 94 times higher compared with all other combinations of depths and sites $(0.00029<$

$275 \mathrm{p}<0.003$; Fig. 6).

276

277 Based on the results obtained from both experiments, we set up a dedicated cleaning station at

278 the edge of the restoration site, away from the transplanted corals, marked by rebars hammered

279 onto the hard substrate at $5 \mathrm{~m}$ intervals. We eliminated diver-assisted cleaning prior to coral

280 transplantation; instead, we attached a nursery rope at the cleaning station, which was set at 0.3

$281 \mathrm{~m}$ above the seabed, resembling the bottom rope shown in Fig. 3 and Fig. 5c. The cleaning

282 station was located at the base of the mooring lines used by the divers to reach the

283 transplantation site, and no significant increase in dive time was involved during its placement.

284 After 48 hours at the cleaning station, the ropes and coral/rope interface were free of barnacles

285 and other biofouling organisms. The corals were also free of mobile invertebrates (except

286 Trapezia sp. crabs). We used the cleaning station technique for 5 months (January-May 2014),

287 and the rate of coral detachment due to fish attacks fell from an initial $16 \%$ to zero.

288

289 Discussion

290 Fish fed on barnacles and other biofouling organisms from the coral nursery ropes located at the

291 transplantation site within 48 hours of deployment of the experimental setup. The diverse fish

292 community at the transplantation site, where 32 species from 4 trophic levels were recorded

293 feeding at the experimental setup, ensured effective animal-assisted cleaning. The Titan

294 Triggerfish (Balistoides viridescens) was the key species because it is capable of crushing the

295 calcareous exoskeletons of the barnacles. The other fish species observed either fed on half-

296 consumed barnacles left behind by $B$. viridescens or fed directly on the biofouling organisms 
297 found on the ropes and at the coral/rope interface. In contrast, the absence of a reef-associated

298 fish community at the nursery site (only 1 species was observed feeding) explains the lack of 299 animal-assisted cleaning of the experimental setup at this location.

301 At the transplantation site, animal-assisted cleaning occurred only on the coral nursery ropes

302 located 0.3 and $2 \mathrm{~m}$ from the seabed. This depth suggests a safe zone or a maximum distance that 303 reef fish will venture away from the protection of the seabed and reef structures to feed.

304 Similarly, diurnal planktivorous reef fishes feed within a maximum distance from the reef; thus, 305 they are able to dive safely back into the reef when exposed to predators (Hobson 1993).

During the field experiments, the fish community video recorded at the transplantation site was a subset of the community observed through visual underwater surveys. Interestingly, 14 species were observed only at the experimental setup and were not recorded during the surveys (Table 1). The remote video recording performed to quantify fish feeding at the experimental setup while the divers were absent allowed us to register species that would otherwise have been

312 hiding or that had fled during the visual underwater surveys. Such differences in census results obtained in the presence and absence of divers are consistent with previous quantifications of the diver effect on diver-based underwater visual fish censuses (Dickens et al. 2011).

Based on the video-recorded observations (Fig. 5, Electronic supplemental material) and known

317 fish diets (Table 1), we deduced the relevant prey items that each trophic group consumed at the 318 experimental setup, thus ensuring the animal-assisted cleaning of biofouling organisms.

319 Herbivores consumed filamentous, coralline and benthic algae. Omnivores consumed vagile 
320 benthic invertebrates and sessile invertebrates (sponges, tunicates, other encrusting organisms).

321 Secondary consumers consumed hydrozoans, bryozoans, sea anemones, echinoderms (sea

322 urchins, ophiuroids), crustaceans (crabs, shrimps, barnacles), mollusks, tunicates, sponges,

323 polychaetes and other worms as well as other vagile benthic invertebrates. Carnivores consumed

324 benthic invertebrates. Because the video recordings were obtained during daylight hours, we

325 were unable to quantify the biofouling predation of twilight and night predators, such as

326 octopuses.

327

328 In summary, the reef fish at the coral transplantation site fed on biofouling organisms (algae,

329 sessile and mobile invertebrates) on the coral nursery ropes prior to transplantation. The recorded

330 barnacle predation rates were $95 \%$ and $83 \%$ on the ropes placed at 0.3 and $2 \mathrm{~m}$ from the seabed,

331 respectively, $48 \mathrm{~h}$ after placement. The fish community at the transplantation site that provided

332 the animal-assisted cleaning service included 32 species from 4 trophic levels: herbivores

333 consumed filamentous, coralline and benthic algae; omnivores and secondary consumers

334 consumed sessile and vagile benthic invertebrates; and carnivores consumed vagile benthic

335 invertebrates. The animal-assisted cleaning technique derived from the experiments described

336 herein consisted of a $48 \mathrm{~h}$ deployment of a coral nursery rope at the transplantation site within

$3370.3 \mathrm{~m}$ of the seabed (the "cleaning station"). Using the cleaning station, we reduced the

338 dislodgement of newly cemented corals by fish from $16 \%$ to zero.

340 We suggest that future research could evaluate the incorporation of the cleaning station

341 technique in two ways. First, the cleaning station could be included as a step prior to coral

342 transplantation at geographic locations outside the Seychelles. The success of the technique will 
343 rely on the existence of key barnacle predators at each geographic location. Key barnacle

344 predators also exist in other regions of the world. For example, in the western Atlantic ocean,

345 stomach content analyses of the Hogfish (Lachnolaimus maximus), a large wrasse (Labridae),

346 and the B atfish (Ogcocephalus nasutus, Ogcocephalidae) has revealed the presence of crushed

347 barnacles (Randall 1967). Therefore, investigating site-specific fish assemblages is essential to

348 determine whether a cleaning station will be effective. Second, nurseries of sexually produced

349 juvenile corals could become temporary cleaning stations. A key bottleneck in the mass culture

350 of sexually produced corals is the high mortality of juveniles during their first 4 months post-

351 settlement (Omori 2005), due to their vulnerability to dying from smothering by filamentous

352 algae (Toh et al. 2013). Therefore, during the first few months after coral settlement, in situ

353 ocean coral nurseries could be placed within $0.3 \mathrm{~m}$ to $2 \mathrm{~m}$ from the seabed at reef sites with an

354 adequate grazer community. However, placing the coral nurseries permanently at a reef site until

355 the corals reach transplantation size, to allow them to benefit from grazer activity, would

356 increase the risk of damage to the nursery corals from coralivorous fish and anthropogenic

357 impacts such as fishing and SCUBA diving (Levy et al. 2010). Therefore, once the juvenile

358 corals have survived the early critical phase, the nurseries could be moved to a more permanent

359 nursery site, away from the reef. Likewise, the nursery corals should be placed closer to the sea

360 surface. Sexually produced coral juveniles would then benefit from the same rapid growth rates

361 observed in the nurseries seeded via asexual coral propagation (Levy et al. 2010, Shafir \&

362 Rinkevich 2010).

363

364 Here, we show that observations of animal behavior, biomimicry (i.e., obtaining inspiration from

365 coral reef cleaning stations) and carefully designed experiments can provide innovative and 
366 sustainable solutions. We recommend such an approach to advance the emerging field of coral

367 reef restoration.

368

369 Acknowledgments

370 We thank S. Beach, M. Beraud, S. Clauson-Kaas, P.H. Montoya-Maya, C. Reveret and K. Rowe

371 for their help during fieldwork; M. Beraud for refinements of the experimental design and fish

372 identification; C. Reveret for his help in the experimental design; P.H. Montoya-Maya for the

373 design of Figure 2; K. Henri and N. Shah for managing the project in which this study was

374 conducted; and P.H. Montoya-Maya, C. Reveret and N. Shah for manuscript comments. 


\section{References}

Benyus JM (2002) Biomimicry: Innovation Inspired by Nature. New York: Harper Perennial

Dickens LC, Goatley CHR, Tanner JK, Bellwood DR (2011) Quantifying relative diver effects in underwater visual censuses. PLoS ONE 6(4): e18965

Frias-Torres S, Goehlich H, Reveret C, Montoya-Maya PH (2015) Reef fishes recruited at midwater coral nurseries consume biofouling and reduce cleaning time in Seychelles, Indian Ocean. African Journal of Marine Science DOI: 10.2989/1814232X.2015.1078259

Froese R, Pauly D (eds) (2014) FishBase. World Wide Web electronic publication. http://www.fishbase.org (accessed 31 December 2014)

Gorlick DL, Atkins PD, Losey GS (1987) Effect of cleaning by Laborides dimidiatus (Labridae) on an ectoparasite population infecting Pomacentrus vaiuli (Pomacentridae) at Enewetak Atoll. Copeia 1987: 41-45

Hill J, Wilkinson C (2004) Methods for ecological monitoring of coral reefs. Townsville: Australian Institute of Marine Science

Hobson ES (1993) Trophic Relationships of fishes specialized to feed on zooplankters above coral reefs. Pages 69-95 In: Sale PF (ed) The ecology of fishes on coral reefs. Academic Press, San Diego, California 
399 Hoegh-Guldberg O (2004) Coral reefs in a century of rapid environmental change.

400 Symbiosis $37(1): 1-31$

401

402

Jackson LE, Barrie JV, Forbes DL, Shaw J, Manson GK, Schmidt M (2005) Effects of

403

the 26 December 2004 Indian Ocean tsunami in the Republic of Seychelles. Report of the

404

Canada UNESCO Indian Ocean Tsunami Expedition, 19 January - 5 February 2005. Geological

405

Survey of Canada, Open File 4539, 73 p.

406

407

Jennings S, Boull DP, Polunin NVC (1996) Habitat correlates of the distribution and biomass of

408

Seychelles' reef fishes. Environmental Biology of Fishes 46: 15-25.

409

410

Ledlie MH, Graham NAJ, Bythell JC, Wilson SK, Jennings S, Polunin NVC, Hardcastle J (2007)

411

Phase shifts and the role of herbivory in the resilience of coral reefs. Coral Reefs 26:641-653

412

413 Levy G, Shaish L, Haim A, Rinkevich B (2010) Mid-water rope nursery-Testing design and

414 performance of a novel reef restoration instrument. Ecological Engineering 36: 560-569.

415

416

Losey GS, Balazs GH, Privitera LA (1994) Cleaning Symbiosis between the Wrasse,

417 Thalassoma duperry, and the Green Turtle, Chelonia mydas. Copeia 1994: 684-690

418 Nelson JS (2006) Fishes of the World, $4^{\text {th }}$ edition. John Wiley \& Sons, New Jersey

419 
420 Omori M (2005) Success of mass culture of Acropora corals from egg to colony in open water.

421 Coral Reefs 24: 563

422

423 Omori M, Iwao K, Tamura M (2007) Growth of transplanted Acropora tenuis 2 years after egg

424 culture. Coral Reefs 27:165

425

426 O'Shea OR, Kingsford MJ, Seymour J (2010) Tide-related periodicity of manta rays and sharks

427 to cleaning stations on a coral reef. Marine and Freshwater Research 61: 65-73

428

429 Precht WF (editor) (2006) Coral reef restoration handbook. CRC Press, Boca Raton, Florida 430

431 Randall JE (1967) Food habits of reef fishes of the West Indies. Studies in Tropical

432 Oceanography 5: 665-847

433

434 Rinkevich B (2006) The coral gardening concept and the use of underwater nurseries; lesson 435 learned from silvics and silviculture. Pages 291-302 In: Precht WF (ed) Coral reef restoration 436 handbook. CRC Press, Boca Raton, Florida

437

438 Shafir S, Rinkevich B (2010) Integrated long-term mid-water coral nurseries: a management 439 instrument evolving into a floating ecosystem. University of Mauritius Research Journal 16: 365$440 \quad 386$ 
442 Shafir S, Edwards A, Rinkevich B, Bongiorni L, Levy G, Shaish L (2010) Constructing and 443 managing nurseries for asexual rearing of corals. Pages49-72 In: Edwards AJ (ed.) Reef 444 rehabilitation manual. Coral Reef Targeted Research \& Capacity Building for Management 445 Program: St Lucia, Australia

446

447 Sokal RR, Rohlf FJ (1995) Biometry: The Principles and Practices of Statistics in Biological 448 Research. $3^{\text {rd }}$ edition. W.H. Freeman and Co., New York

Spalding MD, Jarvis GE (2002) The impact of the 1998 coral mortality on reef fish communities 451 in the Seychelles. Marine Pollution Bulletin 44: 309-332

452

453

Spencer T, Teleki KA, Bradshaw C, Spalding MD (2000) Coral bleaching in the southern

454

Seychelles during the 1997-1998 Indian Ocean warm event. Marine Pollution Bulletin 40:569-

$455 \quad 586$

456

457 Toh TC, Ng CSL, Guest J, Chou LM (2013) Grazers improve health of coral juveniles in ex situ 458 mariculture. Aquaculture 414-415: 288-293

459

460

Woerner J (2011) Integration and Application Network, University of Maryland Center for

461

Environmental Science (http://ian.umces.edu/imagelibrary/)

462

Tables and Figures

Table 1. Video-recorded barnacle and biofouling fish predators interacting with the experimental

464 setup at the transplantation site. Published trophic levels (mean \pm SE) and diets are shown 
465 (Froese \& Pauly 2010; FishBase data, http://www.fishbase.org; Encyclopedia of Life,

466 http://www.eol.org). $\left.{ }^{*}\right)$ Species not recorded during visual underwater surveys of the

467 transplantation site. Species are ordered taxonomically (Nelson 2006).

468

\section{Figures}

470 Fig. 1. The problem. As the number of transplanted corals increases, newly cemented corals are

471 dislodged by hungry fish. The fish attempt to feed on barnacles and vagile invertebrates recruited

472 to the corals during the nursery phase.

Fig. 2. Study area. a. Location of Cousin Island Special Reserve. b. Detail of Cousin Island showing the nursery site and the rehabilitated reef (transplanted reef and control sites, healthy 476 and degraded).

Fig. 3. Experimental setup (testing the cleaning station) at both the nursery (control) and transplantation (treatment) sites. a. Schematic representation of the experimental setup showing the range of depths and elements. b. Photograph of the setup with a diver. Credit for coral symbols: Woerner (2011). Photo credit: Casper van de Geer. See video in Supporting Information.

Fig. 4. Fish assemblages. Fish families, number of species per family, and trophic levels at the transplantation site during A) underwater visual surveys (November 2013) and B) video recordings of the experimental setup (December 2013). Insets in A) and B) show trophic groups

486 (number of species per group indicated). 
488 Fig. 5. Animal-assisted biofouling cleaning. a. Barnacle predation at the transplantation site: the 489 circle shows a clump of barnacles before (left) and $48 \mathrm{~h}$ after placement (right).

490 b. Titan Triggerfish, Balistoides viridescens, shown in the foreground of the experimental setup.

491 c. Reef fish lined up feeding on the $0.3 \mathrm{~m}$ coral rope at the transplantation site. Photo credit:

492 Casper van de Geer. See video in Supporting Information.

493

494 Fig. 6. Animal-assisted biofouling cleaning. Average barnacle predation per depth at the nursery 495 (control) and transplantation (treatment) sites. Bars indicate standard error $(\mathrm{n}=3)$.

496

497 Supporting Information

498 Video. Experimental setup. Overview of the experimental setup (testing of the cleaning station)

499 shown in Fig. 3 and fish species described in the text feeding on the coral nursery ropes. Video 500 credit: Casper van de Geer. 
Table 1 (on next page)

Video-recorded barnacle and biofouling fish predators interacting with the experimental setup at the transplantation site

Table 1. Video-recorded barnacle and biofouling fish predators interacting with the experimental setup at the transplantation site. Published trophic levels (mean $\pm \mathrm{SE}$ ) and diets are shown (Froese \& Pauly 2010; FishBase data, http://www.fishbase.org; Encyclopedia of Life, http://www.eol.org). (*) Species not recorded during visual underwater surveys of the transplantation site. Species are ordered taxonomically (Nelson 2006). 


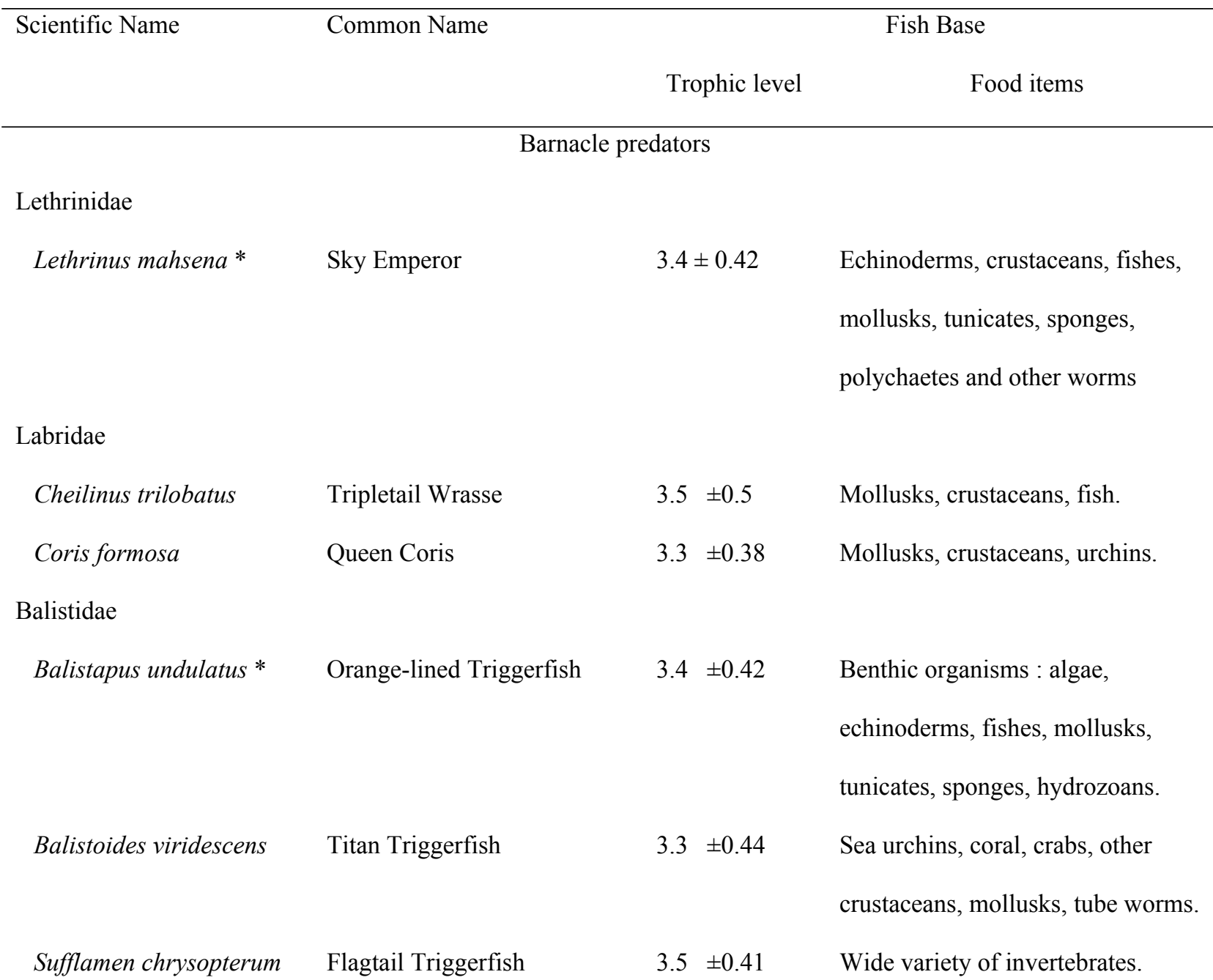

Bio-Fouling (excluding barnacles) predators

Lutjanidae

Lutjanus lemniscatus * $\quad$ Yellowstreaked Snapper $\quad 4.0 \pm 0.65 \quad$ Benthic invertebrates

Pomacanthidae

Pomacanthus imperator Emperor Angelfish

$2.7 \pm 0.00 \quad$ Sponges, tunicates, other encrusting

organisms

P. semicirculatus

Semi-circle Angelfish

$2.5 \pm 0.0$

Sponges, tunicates, algae

Chaetodontidae

Chaetodon auriga

Threadfin Butterflyfish

$3.2 \pm 0.5$

Polychaetes, sea anemones, coral

polyps, algae 


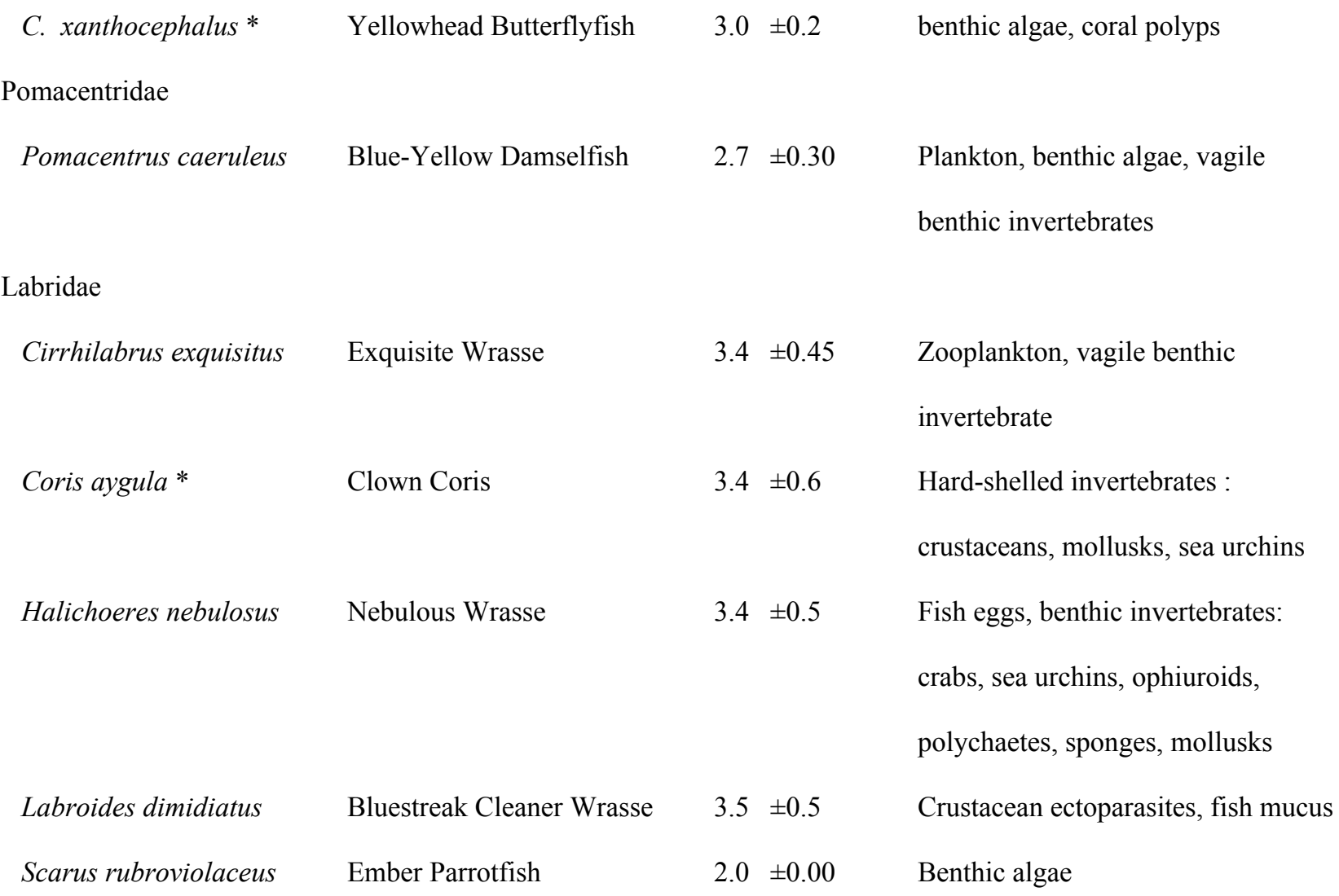

Pinguipedidae

Parapercis hexophtalma

Speckled Sandperch

$3.6 \pm 0.3$

crabs, shrimps small fish

Bleniidae

Aspidontus dussumieri * Slender Sabretooth Blenny $\quad 2.0 \pm 0.00 \quad$ Algae, detritus

Acanthuridae

Acanthurus leucocheilus* Palelipped Surgeonfish

$2.0 \pm 0.0$

Algae, detritus

A. nigricauda

Blackstreak Surgeonfish

$3.0 \pm 0.40$

biofilm on sandy surfaces

A. tennenti

Tennent's Surgeonfish

$2.0 \pm 0.00$

Benthic algae.

Zebrasoma desjardini *

Sailfin Tang

$2.0 \pm 0.0$

Filamentous algae, macroalgae, plankton

Zanclidae

Zanclus cornutus

Moorish Idol

$2.5 \pm 0.00$

sponges, sessile invertebrates

Siganidae

Siganus argenteus

Forktail Rabbitfish

$2.0 \pm 0.0$

Algae 

S. stellatus *
Honeycomb Rabbitfish
$2.7 \pm 0.30$
Benthic seaweeds

Monacanthidae

Cantherhines

Spectacled Filefish

$3.5 \pm 0.37$

Benthic organisms

fronticinctus *

Ostraciidae

Lactoria cornuta *

Longhorn Cowfish

$3.5 \pm 0.37$

Benthic invertebrates

Tetraodontidae

Arothron meleagris * Guineafowl Puffer

$3.4 \pm 0.6$

Tips of branching corals, sponges, mollusks, bryozoans, tunicates, forams, algae, detritus

Canthigaster valentini

Black Saddled Toby

$2.8 \pm 0.30$

Filamentous green, brown and

coralline red algae, tunicates, corals, bryozoans, polychaetes, echinoderms, mollusks

Diodontidae

Diodon hystrix *

D. liturosus *
Porcupinefish

Black-blotched

Porcupinefish
$3.4 \pm 0.5$

Hard shelled invertebrates : sea urchins, gastropods, hermit crabs

$3.4 \pm 0.6$ Crustaceans and mollusks. 
1

The problem

Fig. 1. The problem. As the number of transplanted corals increases, newly cemented corals are dislodged by hungry fish. The fish attempt to feed on barnacles and vagile invertebrates recruited to the corals during the nursery phase.

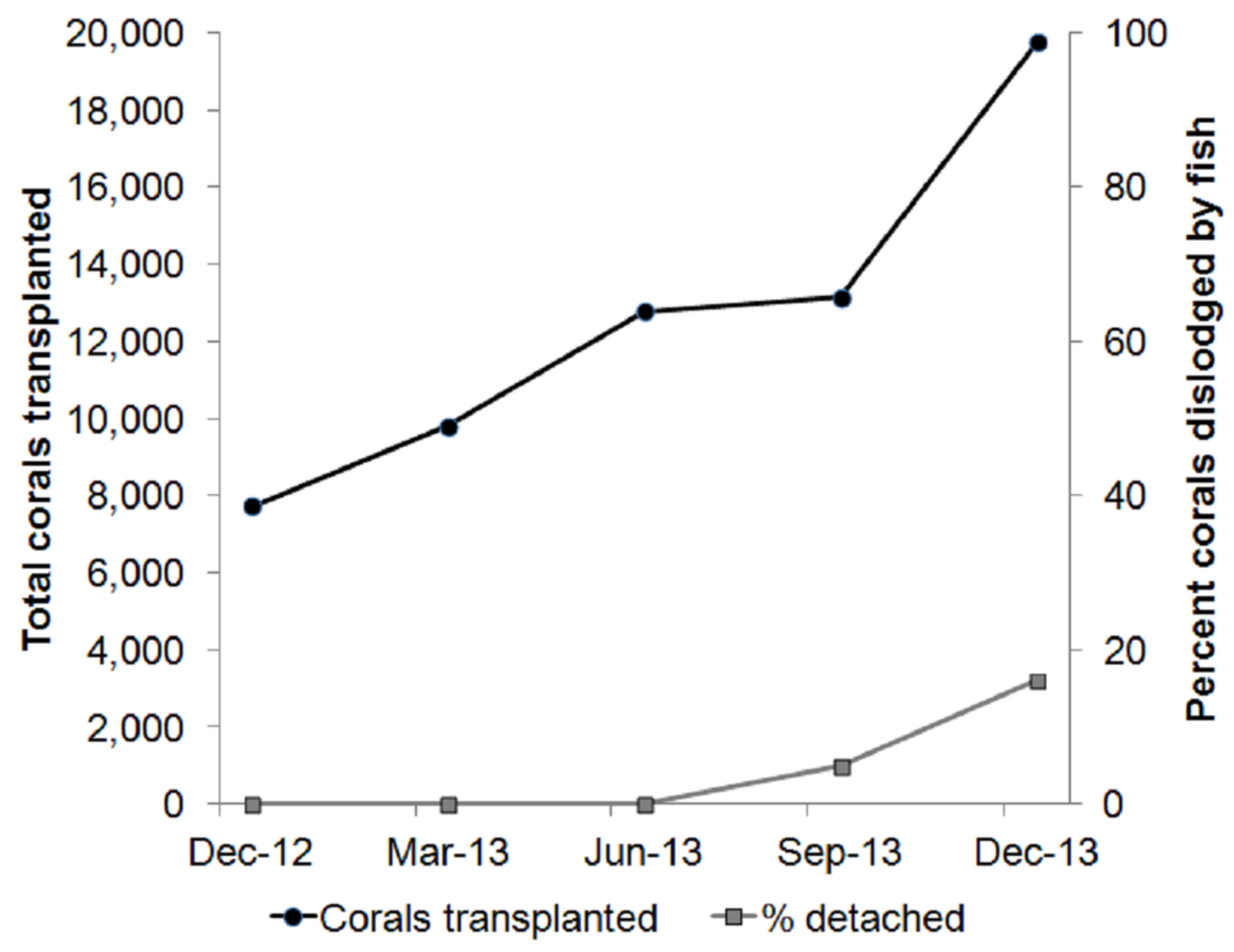


2

Study area

Fig. 2. Study area. a. Location of Cousin Island Special Reserve. b. Detail of Cousin Island showing the nursery site and the rehabilitated reef (transplanted reef and control sites, healthy and degraded).
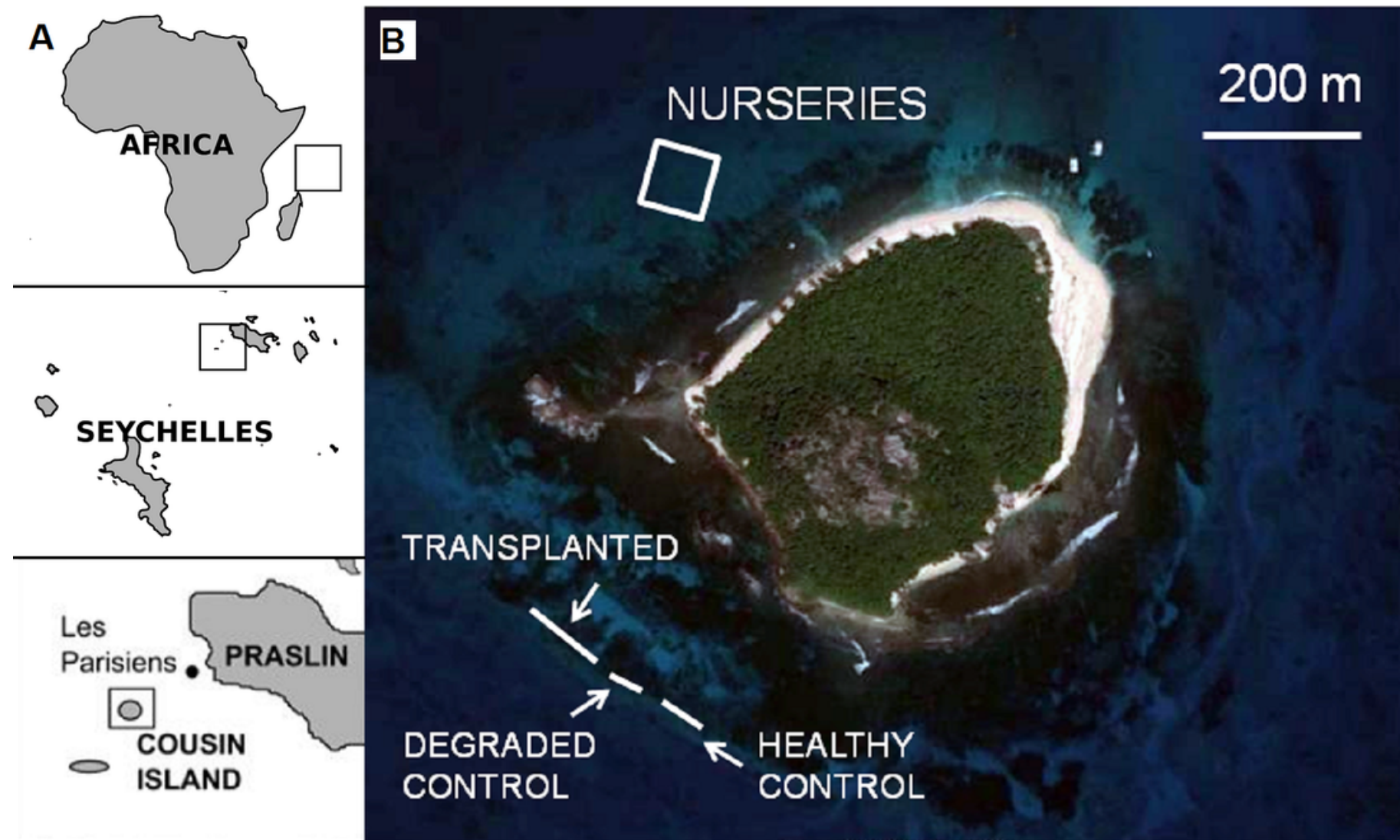


\section{3}

\section{Experimental setup}

Fig. 3. Experimental setup (testing the cleaning station) at both the nursery (control) and transplantation (treatment) sites. a. Schematic representation of the experimental setup showing the range of depths and elements. b. Photograph of the setup with a diver. Credit for coral symbols: Woerner (2011). Photo credit: Casper van de Geer. See video in Supporting Information.
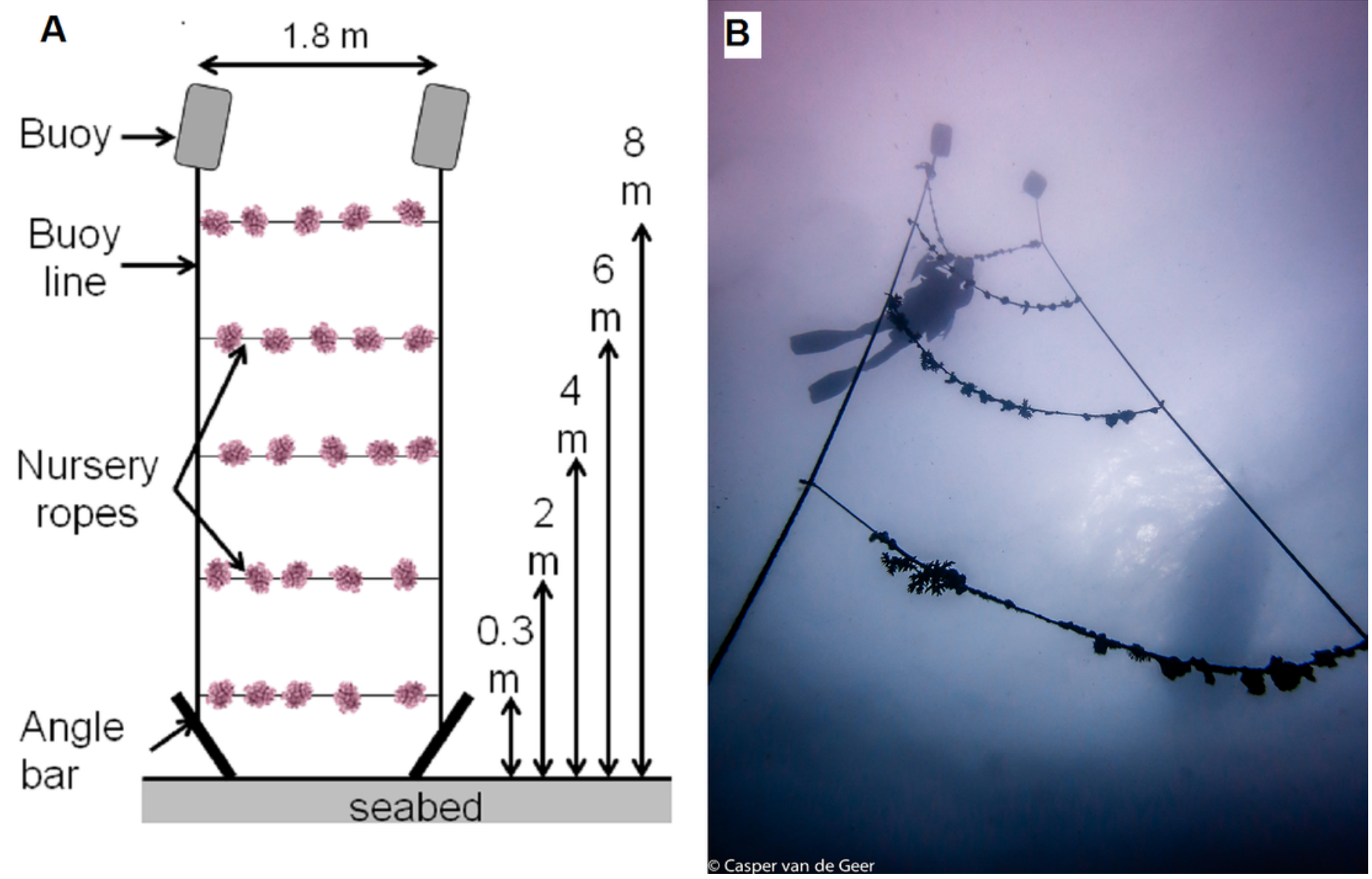
4

Fish assemblages

Fig. 4. Fish assemblages. Fish families, number of species per family, and trophic levels at the transplantation site during A) underwater visual surveys (November 2013) and B) video recordings of the experimental setup (December 2013). Insets in A) and B) show trophic groups (number of species per group indicated). 


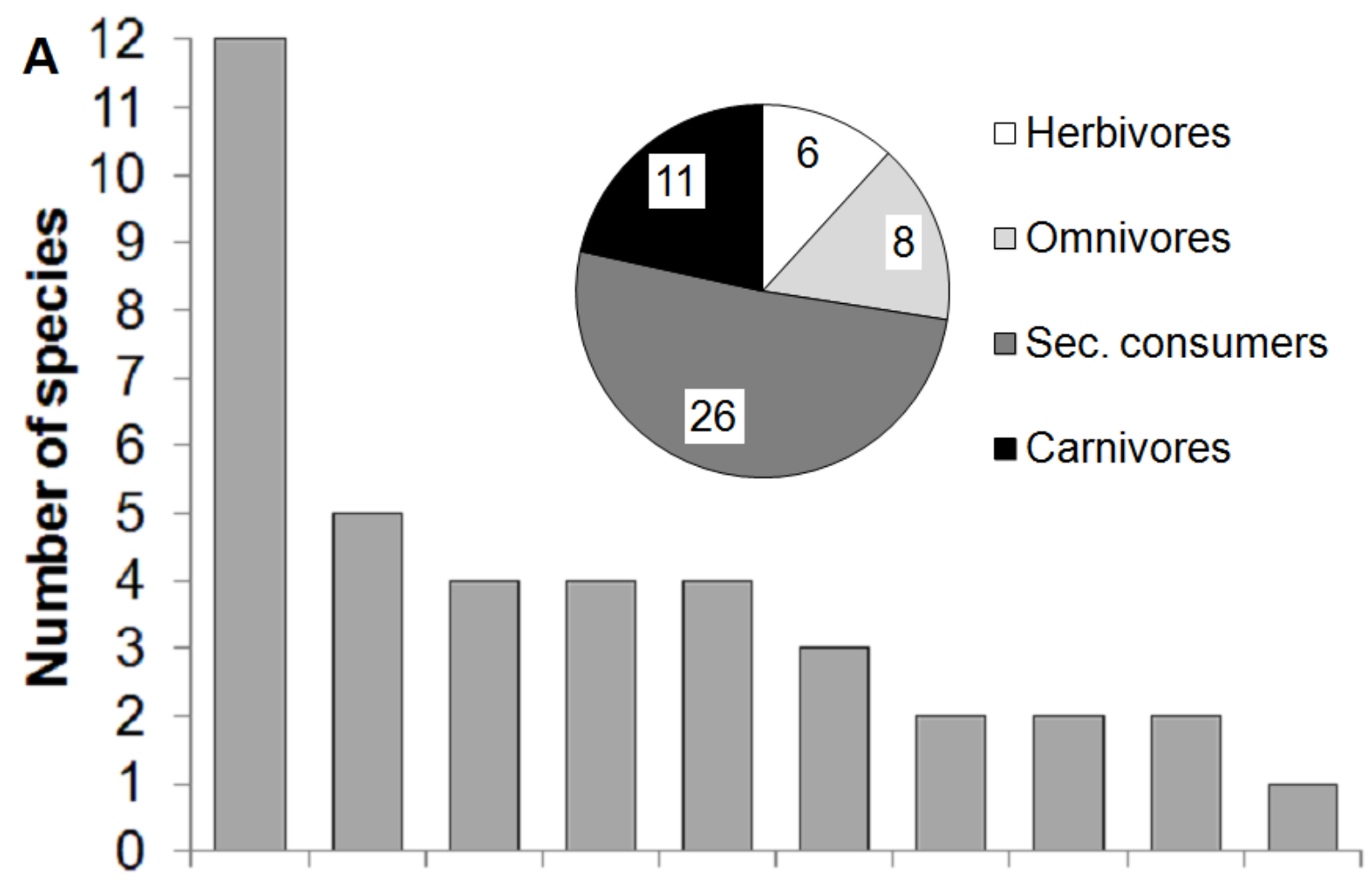

Lab Aca Ser Pom Cha Bal Mul Poc Mic Oth Family

B

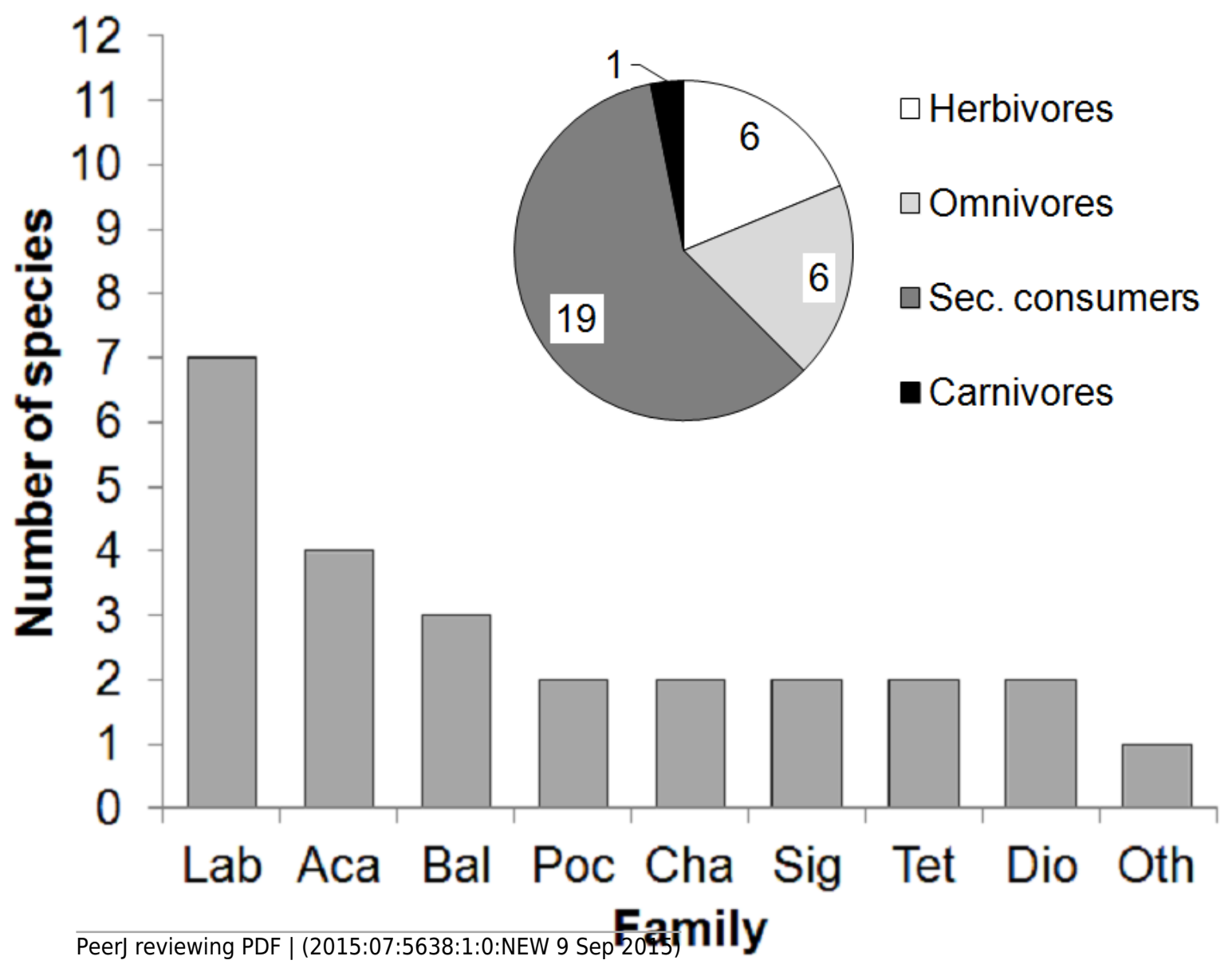




\section{5}

Animal-assisted biofouling cleaning

Fig. 5. Animal-assisted biofouling cleaning. a. Barnacle predation at the transplantation site: the circle shows a clump of barnacles before (left) and $48 \mathrm{~h}$ after placement (right). b. Titan Triggerfish, Balistoides viridescens, shown in the foreground of the experimental setup. $\mathbf{c}$. Reef fish lined up feeding on the $0.3 \mathrm{~m}$ coral rope at the transplantation site. Photo credit: Casper van de Geer. See video in Supporting Information. 
PeerJ Reviewing Manuscript
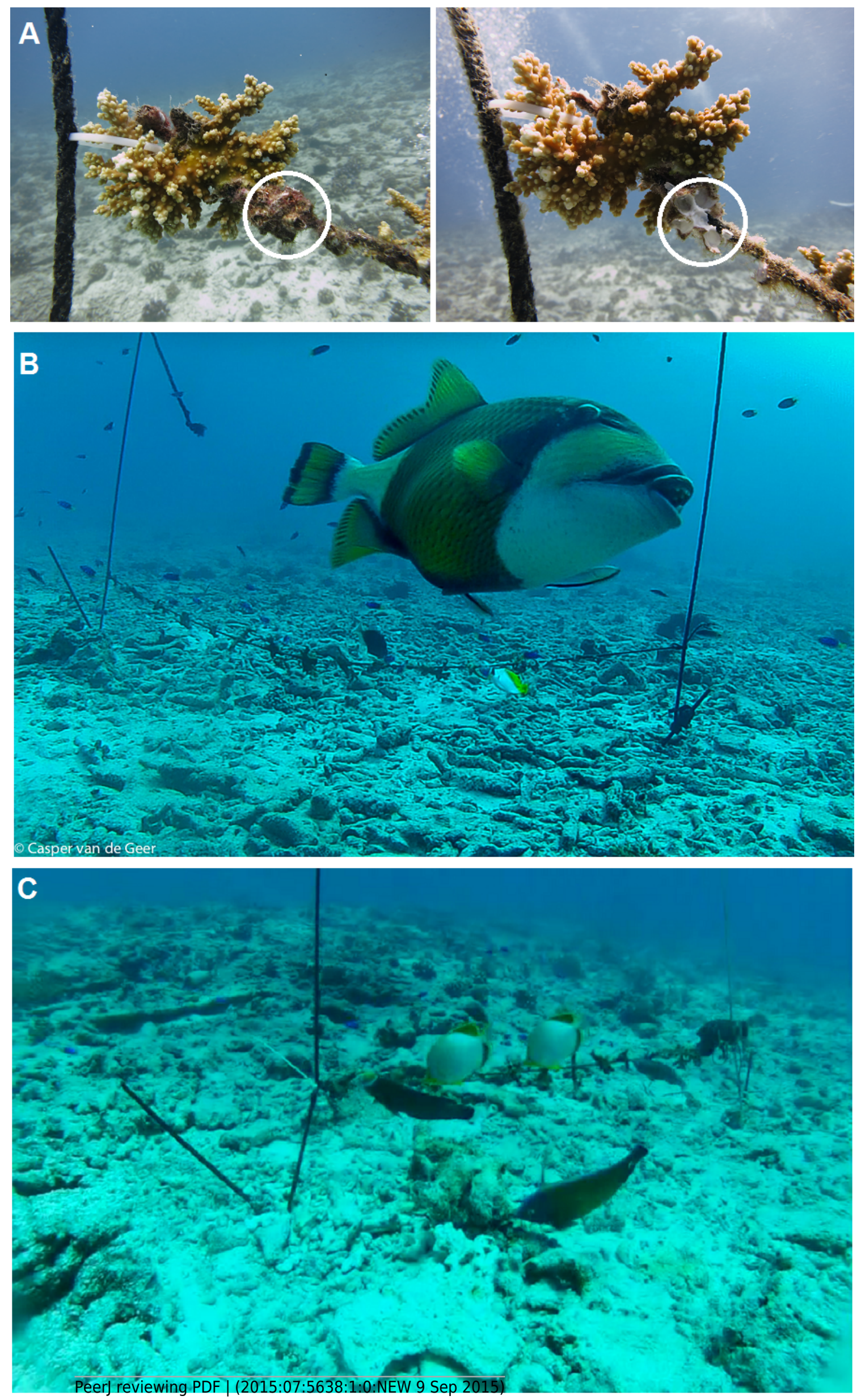
6

Average barnacle predation

Fig. 6. Animal-assisted biofouling cleaning. Average barnacle predation per depth at the nursery (control) and transplantation (treatment) sites. Bars indicate standard error $(n=3)$.

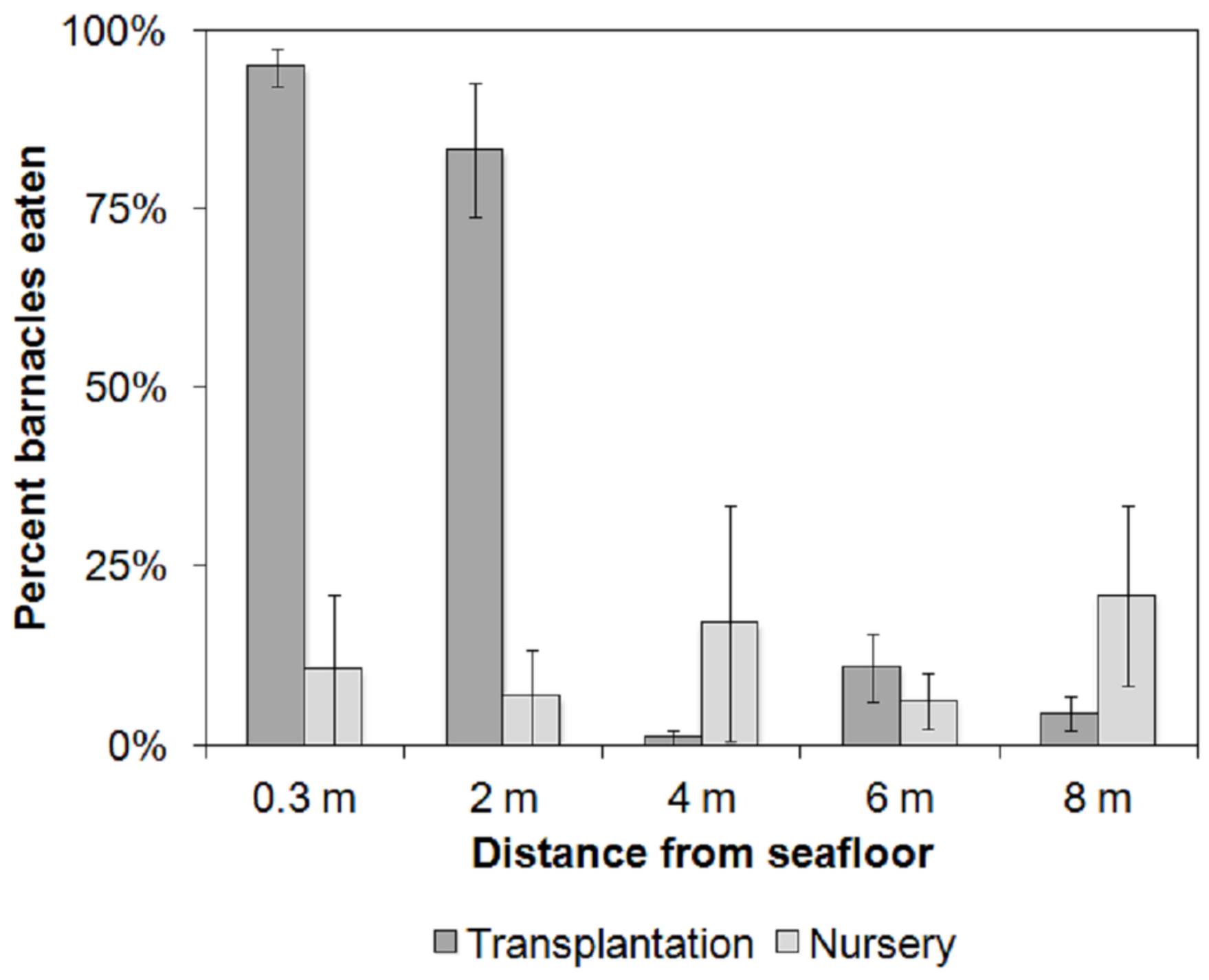

